\title{
DEL CAMBIO DE AUTOR AL AUTOR ESPECTRAL ${ }^{1}$
}

\author{
Gabriela GARCÍA HUBARD \\ Universidad Nacional Autónoma de México
}

\begin{abstract}
Pensar, analizar, inventar [...] no son actos anómalos, son la normal respiración de la inteligencia.
\end{abstract}

Jorge Luis Borges

\begin{abstract}
7 odos lo sabemos, pese a la muerte del Autor (con mayúscula) el autor (con minúscula) sigue aquí, tomando nuevos rostros en estos inicios del siglo XXI. Si bien es cierto que, como 1 asegura Roland Barthes, la escritura es donde se pierde toda identidad (1968: 63), ¿qué nos
\end{abstract} queda del autor? Puesto que el escritor se limita a imitar un gesto no original y siempre anterior (1968: 67), tendríamos que empezar por reconocer que el mismo texto de Barthes, «La muerte del autor», también está imitando un gesto no original y siempre anterior. Dicho de otra forma, lo que dice Barthes sobre la escritura en general, no puede excluir a su propio texto: «un texte est fait d'écritures multiples» (1968: 69). Aunque en una primera lectura podamos reconocer esa escritura múltiple a través de los autores que cita explícitamente (Balzac, Proust, Valery, Mallarmé, Brecht, de Quincey, Baudelaire, Vernant, etc.), también podríamos rastrear, por lo menos y sin mayor dificultad: la heteroglosia de Bajtin, la escritura neutra de Blanchot, la fuerza discursiva de Foucault, el sujeto clivado de Lacan y el espectro de Derrida: «l'écriture est destruction de toute voix, de toute origine» (Barthes, 1968: 63) ${ }^{2}$. Y, pese a todo, por todas las razones que ofreció Foucault en su mítico texto sobre el autor, nos seguimos refiriendo a «La muerte del autor» de Roland Barthes.

Una de las maneras más evidentes de reconocer que el lugar que ocupa el autor continúa siendo uno de los más controvertidos dentro de los estudios literarios (Compagnon, s/f: 1), consiste en aceptar que no leemos un libro ni vemos un cuadro de la misma forma cuando sabemos quién es el

\footnotetext{
${ }^{1}$ Este artículo es resultado del trabajo realizado en el marco de los siguientes proyectos de investigación: ¿Corpus auctoris? Análisis teórico-práctico de los procesos de autorización de la obra artístico-literaria como materialización de la figura autorial (FFI2012-33379) que lleva a cabo el Grupo de Investigación Consolidado Cuerpo y Textualidad (2009 SGR 651) de la Universitat Autònoma de Barcelona; y de Horizontes teóricos y críticos en torno a la figura autoral contemporánea (clave IN405014-3), del Programa de Apoyo a Proyectos de Investigación e Innovación Tecnológica (PAPIIT), con financiamiento de la DGAPA-UNAM.

${ }^{2}$ Recordemos que «La muerte del autor» de Roland Barthes fue publicado en 1968, mientras que La voz y el fenómeno de Jacques Derrida fue publicado un año antes. Aunque en realidad sea imposible buscar el «origen» de la destrucción o deconstrucción de esa «VOz originaria» podríamos hablar de la escritura múltiple de Tel Quel. Pero sin lugar a dudas la idea de que «la escritura es la destrucción de toda voz, de todo origen» resuena de manera particular con el texto derridiano y una relectura del texto de Barthes en eco con La voz y el fenómeno muestra otro rostro de la muerte del Autor. Este guiño será retomado más adelante.
} 
autor y la importancia que tiene. Esta es una de las tantas cosas que demuestra Pierre Bayard en su libro Et si les oeuvres changeaient d'auteur? (2010). Inspirado en «Pierre Menard, Autor del Quijote» de Borges, Bayard afirma que resulta sorprendente que los cambios de autor sean practicados de manera tan poco frecuente por los críticos hoy en día, agregando que si comúnmente remplazamos «l'auteur de l'œuvre, largement inaccessible, par la personne physique derrière laquelle il se dissimule, pourquoi ne pas faire un pas de plus et le remplacer -mais en assumant cette fois clairement le geste- par un autre auteur qui nous semblerait, pour telle ou telle raison, plus approprié à l'œuvre?» (Bayard, 2010: 11)

En este texto Bayard también sostiene que la noción de autor funciona todavía como un mito y un tabú, y señala discretamente, en una nota a pié de página, que es notable que ni Barthes ni Foucault, en sus célebres textos en donde ponen en duda la noción de autor, hayan tenido la audacia de remplazar unos autores por otros (Bayard, 2010: 13). Sin embargo, habría que reconsiderar, como lo acabamos de sugerir en el primer párrafo, que quizás Barthes sí lo hizo, pero de for ma múltiple: al mismo tiempo sutil y astuto. La muerte del Autor, ya lo sabemos, forma parte de un momento histórico, político, ideológico radical propio del 68 , rechazando la autoridad del padre, de dios y la ley que dirige y ordena. Pero sobre todo retoma la falacia intencional señalada por los Nuevos Críticos anglosajones, refutando así la idea de que la intencionalidad del autor puede realmente llegar a su telos, a su objetivo, guiando la interpretación rumbo a un significado final. Pero si esta misma muerte también señala uno de los puntos cruciales rumbo al llamado postestructuralismo, entonces ¿dónde y cómo ubicar el texto de Bayard sobre los cambios de autor?, ¿en un punto intermedio junto a Genette y Booth?, ¿en otra latitud de los diálogos actuales sobre el autor en Francia (Meizoz, Maingueneau, Amossy)?, ¿en un movimiento deconstructivo o más bien en un «después» del postestructuralismo?

Basta recordar otros tres títulos de Bayard (Comment améliorer les auvres ratées?, Comment parler des libres que l'on n'a pas lus? y Le plagiat par anticipation) para darnos cuenta que retoma el mismo tono irónico, divertido y provocador, pocas veces visto en este tipo de textos, para continuar su proyecto teórico-crítico. En su artículo «Pierre Bayard's Wormholes», Warren Motte señala que Bayard ocupa una posición rara como crítico y teórico: «He writes in a conditional hypothetical mode rather than a declarative one, keenly aware of how very mobile literary objects are, at their best». Escribiendo tanto para especialistas como para el público en general, sin duda ha ayudado a expandir el horizonte de posibilidades del quehacer crítico (Motte, 2011: 268). En esta expansión que señala Motte radica tanto la agudeza de pensamiento y análisis como el desconcierto que pueden transmitir los textos de Bayard, ya que asegurar que su obra toma riesgos buscando nuevas formas a través de la experimentación, nos hace pensar que estamos hablando de un escritor de ficción en lugar de un teórico y/o crítico. Y en este punto radica el desconcierto, pues el mismo Bayard ha confesado que busca desplazar la frontera entre teoría y ficción, ficcionalizando la interpretación (Motte, 2011: 286) y abogando por un acto crítico menos restrictivo, «one that is not altogether innocent of the delirium of interpretation» (Motte, 2011: 276). 
Las fronteras tan problemáticas entre realidad y ficción que siempre han acechado a la literatura, este vez habitan en el ámbito teórico, no como un objeto externo listo para ser analizado y discutido, sino como la forma misma de la crítica. Sin duda el texto de Borges que funge como detonador y que se sitúa entre los límites del ensayo y la ficción, haciendo de la crítica una ficción (Compagnon, s/f: 10), marca el inicio de esta aventura. Pero mientras Borges desplaza las fronteras dentro de la ficción, la audacia y el ingenio de Bayard consiste en desplazarlas hacia el acto crítico: delirante pero también enriquecedor. Pues en su proyecto no todo es un simple juego de la imaginación, y precisamente trataremos de indagar hasta dónde llaga esta propuesta aparentemente descabellada.

\section{I}

Los primeros cambios de autor que nos presenta Bayard en su libro ¿Y si las obras cambiaran de autor? en realidad remiten a la historia de la literatura (no tradicional), o incluso podríamos decir a una suerte de historia de la problemática autoral, en dónde señala algunas de las atribuciones erróneas o confusas de autores que se han realizado a lo largo del tiempo; este gesto le permite al crítico introducirnos en su juego de forma seria y rigurosa. La idea, por ejemplo, de que La Odisea fue imaginada por una mujer y no por un hombre la defendió Samuel Butler, un novelista británico del siglo XIX, eminente helenista y gran conocedor del mundo griego, en su libro El autor de la Odisea. Según Butler mientras que La Iliada da preponderancia a los hombres, La Odisea lo hace con las mujeres. La imagen de la mujer es más positiva en ésta última y la mirada puesta sobre los hombres es femenina e incluso maternal: las mujeres son las que saben y protegen, y en ningún momento los hombres rescatan a una mujer en apuros. Por eso, para el helenista, «loin d'être l'homme d'âge mûr que l'on se plaît parfois à imaginer, l'écrivaine était une jeune femme peu avertie des jeux de l'amour, qu'elle décrit avec une certaine maladresse, comme si elle était inexpérimentée en la matière» (Bayard, 2010: 23), además de que desconoce la psicología masculina y no tiene conocimiento de la vida material.

Lo más interesante es que esto que llama «derecho a la ficción», trabajo creativo o alegre error como apertura de espíritu, provoca una relectura de La Odisea que nos hace descubrir ciertos aspectos de la obra que de otra forma quizás no hubiéramos notado. Así es como Bayard nos empieza a convencer de que la construcción de un autor requiere un trabajo de creación, puesto que «tout nom d'auteur est un roman. Loin d'être un simple mot, il attire autour de lui toute une série d'images ou de représentations» (Bayard, 2010: 27), que evidentemente condiciona la lectura. Aquí la idea de la representación o de la imagen del autor que construimos no es nueva, ya que como bien sabemos el lector necesita de un interlocutor imaginario al cual construye en el acto de la lectura. Diaz, entre otros críticos, desanquilosa así la figura de Barthes asesino del autor quien, apenas unos años después de la tan mentada muerte, declara «el deseo» de autor re-contextualizando el crimen:

Comme institution l'auteur est mort: sa personne civile, passionnelle, biographique, a disparu; dépossédée, elle n'exerce plus sur son œuvre la formidable paternité dont l'histoire littéraire, 
l'enseignement, l'opinion avaient à charge d'établir et de renouveler le récit: mais dans le texte, d'une certaine façon, je désire l'auteur. (Barthes 1973: 45-46).

En realidad el Autor que muere es la persona plenamente responsable, la autoridad de la institución, sin embargo, nos queda un «palimpseste de rumeurs et d'échos», así como una persona «civile, sociale et fantasmatique de l'écrivain»: «Que l'intellectuel et l'écrivain aient une fonction, mais aussi un "rôle" et une "image", une identité scénique et spéculaire, qu'il soit aussi mythe et fantasme offert à ses lecteurs, et non seulement transparent sujet d'énonciation, c'est ce que toute l'œuvre de ce Barthes latéral nous suggère, du début à la fin» (Diaz, 1993: 77-78). Ese écrivain ${ }^{3}$ que parece tomar el relevo del autor (con minúscula) es el papel que el gran Barthes ocupará él mismo tanto en la historia como en la actualidad, «comme un écrivain à venir. Un écrivain fantôme. Un “écrivain-comme-fantasme"» (Diaz, 1993 : 85).

Retengamos por el momento el exceso de sentido y la complicidad etimológica entre fantasmes (con todo y «el deseo» de autor) y fantômes, nada ajena a la noción de autor. Basta señalar algunas acepciones según el CNRTL para hacerlas resonar aún más en nuestro contexto: Fantasme. construcción imaginaria que permite al sujeto satisfacer sus deseos; representación imaginaria marcando una ruptura con la realidad consciente; visión alucinatoria. Fantôme. aparición fantástica; manifestación de una persona fallecida; recuerdo persistente, sentimiento obsesivo; creación de la imaginación, ser ideal, entre otras. Frente a los nuevos debates en torno del autor resulta imposible ignorar esta alianza, por lo que volveremos más adelante a este tema cuando propongamos la figura de «autor espectral».

Pero primero regresemos al texto de Bayard pues es evidente que, como tantos otros críticos, está en deuda tanto con Barthes como con Foucault por la pluralidad del ego y del alter ego, así como por la función de autor como construcción, alejado del individuo real. La función de autor moderno en manos de Foucault no produce y garantiza el sentido, sino que lo abre a una proliferación de sentidos ya que permite ciertas operaciones de lectura y de interpretación (Compagnon, s/f: 5). Bayard recuerda el hecho de que los libros pueden leerse en función del autor (asignado), demostrando nuevamente que los textos pueden decir mucho más de lo que imaginamos. Y al igual que Foucault, Bayard seguramente ha sido criticado por la audacia (locura) de sus relaciones.

No podemos conocer la identidad de Homero y de hecho se piensa que fueron varios autores en épocas diferentes los creadores de La Odisea. Por lo tanto, no es absurdo privilegiar aquella teoría que aporte más a las lecturas de hoy en día ${ }^{4}$. Acercándose a la noción de autor implícito, el autor imaginario del que nos habla Bayard está construido a través de una serie de imágenes aproximativas del autor real. Pero con la idea de que esta construcción es un acto creativo, su proyecto va a dar un

\footnotetext{
3 «On doit désormais compter avec la présence difficilement réductible au signe et au texte de celui qu'il convient d'appeler plutôt l'écrivain: celui-ci se voit attribuer une triple identité: éthologique, mythologique et fantasmatique» (Diaz, 1993: 78).

${ }^{4}$ Aquí una vez más recordamos a Barthes para quien el trabajo del crítico no consiste en descubrir el sentido oculto del texto, sino construir inteligibilidad para nuestro tiempo. Y también a Iser, aunque por otro camino, para quien la tarea del crítico no pretende explicar el significado del texto sino sus efectos en el lector.
} 
paso más al remplazar un autor imaginario con otro autor imaginario (Bayard, 2010: 39-40). El carácter novedoso se inscribe entonces en la gran permeabilidad entre ficción y realidad con la que trabaja, pues «il ne sert dès lors à rien d'essayer de contrôler les frontières entre ces mondes, car de multiples passages s'effectuent, et cela dans les deux sens» (Bayard citado en Motte, 2011: 288).

En L'Affaire du chien des Baskerville Bayard ya había señalado que el lenguaje no permite separar a los seres reales de los personajes imaginarios, y puesto que el paso se efectúa en los dos sentidos, las personas reales pueden entrar en la ficción, y los personajes ficticios ser independientes. Motte retoma en este contexto la metalepsis: figura narrativa trabajada por Genette y evocada por Bayard en Demain est écrit (2005: 87), la cual permite el deslizamiento de un nivel narrativo al otro.

Le passage d'un niveau narratif à l'autre ne peut en principe être assuré que par la narration, acte qui consiste précisément à introduire dans une situation, par le moyen d'un discours, la connaissance d'une autre situation. Toute autre forme de transit est, sinon toujours impossible, du moins toujours transgressive. $[\ldots]$

Le plus troublant de la métalepse est bien dans cette hypothèse inacceptable et insistante, que l'extradiégétique est peut-être toujours déjà diégétique, et que le narrateur et ses narrataires, c'est-à-dire vous et moi, appartenons peut-être à quelque récit (Genette, 1972: 243-245).

Un tipo de metalepsis ${ }^{5}$ (intrusión de una diégesis en otra diégesis) es precisamente lo que encontramos en ¿Y si las obras cambiaran de autor? Lo que Bayard hizo en otro momento con los personajes de ficción, ahora lo hace con los autores irremediablemente remitiéndonos a múltiples diégesis y «realidades»; «la part d'invention que comporte toute activité de lecture ne s'arrête pas à l'œuvre, elle s'étend jusqu'à l'auteur» (Bayard, 2010: 28). Pensar en la lectura como un tipo de reescritura tampoco es una novedad, pero sí lo es la radicalización de ese poder inventivo y juguetón con el que trabaja, en vías, nos parece, de una infinita riqueza textual, pero también de una problematización de la figura autoral. Ya no se trata simplemente de poner el dedo sobre la división clásica entre ficción y realidad, sino que la ficción invade, contamina, no solo el acto de lectura, sino también la teoría; el mejor ejemplo sería la forma en que convierte el tropo literario de la metalepsis, en una forma crítica, en dónde ya no diferenciamos entre el concepto y su ejemplificación: la metalepsis teórica permite una serie de tránsitos inesperados.

Conocidos son los debates sobre si Hamlet fue escrito por Shakespeare o por ejemplo por Edward de Vere; de la misma manera mucho se ha cuestionado si las obras más famosas de Molière fueron escritas en realidad por Corneille, empezando por el Don Juan. Desbordando una vez más la ficción y lo literario, las atribuciones controvertidas de autores pueden tener otras consecuencias, como bien lo señala Bayard, más allá de la teoría literaria y de la historia de la literatura. Si Freud

\footnotetext{
5 «Among all of these critics and theoreticians, Bayard is undoubtedly closest to Genette in the way he conceives of metalepsis. Or, more accurately, to the Genette who gradually came to view metalepsis as a phenomenon broadly distributed in the everyday world, and thus rather less anomalous than he had once imagined it to be. Yet Bayard's stance seems to me more radical than Genette's, insofar as his wormholes cannot be reduced to mere tropes. While the figure of metalepsis is undoubtedly involved in the way that Bayard conceives them, and while some of the gestures that they describe are certainly metaleptic in character, his wormholes are more complex than that, both in their conception and in the manoeuvres that they enable. In fact, they are nothing less than the pathways of a fully integrationist vision of literature» (Motte, 2011: 286). Este texto también ofrece una clara explicación de la manera en que la concepción de metalepsis evoluciona en la obra de Genette.
} 
apoyó durante toda su vida la idea de que Edward de Vere fue el verdadero autor y no Shakespeare, se debió a que sus propias teorías psicoanalíticas se veían reforzadas con esta atribución, ya que la vida de de Vere reencarna el complejo de Edipo de forma magistral (Bayard, 2010: 30-40)6.

Pero para Bayard estos debates históricos sobre el autor no abordan la pregunta más importante: ¿se gana algo desde el punto de vista literario?, ¿el texto se beneficia de alguna manera con este cambio de autor? Realizando entre líneas una crítica irónica a este tipo de debates que ponen toda su atención en el autor e, insisto, forman parte de la historia de la literatura y de la crítica, Bayard propone que en lugar de centrarse en la verdad histórica, habría que preguntarse sobre las ganancias estéticas (Bayard, 2010: 46) ${ }^{7}$. Y es precisamente lo que hace. Con el cambio de autor las obras aparecen como algo diferente, sin haber sido modificadas. El texto resuena de otra forma y la teoría literaria también.

\section{II}

Mientras que en la primera parte del libro Bayard se ocupa de una suerte de revisión histórica, la segunda parece poner el acento en una noción espinosa: el estilo. Después de las teorías de principios del siglo XX (Formalistas, algunos Nuevos Críticos y Estructuralistas) que aíslan, en diferentes grados y formas, el objeto literario de su contexto, lo intra-textual de lo extra-textual ¿cómo hablar del estilo? ¿No es el estilo aquello que es, al mismo tiempo, interno y externo, parte del texto y del autor? En este contex to Bayard retoma ciertas atribuciones de autores extraordinarias, mostrando así la dificultad de tener la certitud que normalmente se pretende del autor. Pero en esta ocasión el cambio (ya sea parcial o en su totalidad) se debe a un interés literario pocas veces visto (Bayard, 2010: 52). En los tres casos que nos presenta explora tres puestas en perspectiva diferentes: Con Romain Gary estamos frente a un cambio nominal; con Boris Vian, espacial; y con Lewis Carroll, temporal, provocando en los tres inflexiones de lecturas que de otra forma no hubieran sucedido (Bayard, 2010: 79).

Romain Gary ya era un autor conocido cuando publica Gros-Câlin firmado por Emile Ajar: «L'inconvénient du nom d'auteur, comme le comprendra parfaitement Romain Gary, surtout quand il est unique, est de geler l'identité, en la restreignant à une partie d'elle-même, et en immobilisant les images extérieures qui en sont données. Il n'est pas une précision, mais bien davantage une restriction» (Bayard, 2010: 70). En esa obsesión por deshacerse de la etiqueta que ya le habían asignado como autor con un estilo determinado, no solo usa el pseudónimo de Ajar, sino que le pide a su sobrino que le preste cuerpo a este autor inventado. Lo notable reside en que los lectores no solo fueros engañados con el tema de la identidad, sino también con una escritura aparentemente diferente que, retrospectivamente, logró modificar la visión que se tenía de los libros anteriores de Gary.

\footnotetext{
${ }^{6}$ «Ainsi, au Shakespeare réel, lequel est à jamais introuvable, Freud substitue un Shakespeare imaginaire, qui sert pour une part ses fantasmes [...] mais appuie surtout ses intérêts théoriques» (Bayard: 2010, 37. Las cursivas son nuestras). ${ }^{7}$ Es una pena, sin embargo, que el texto de Bayard no haya retomado ningún ejemplo de anonimato autoral.
} 
Il est cependant indiscutable qu'on ne lit plus aujourd'hui Gary et les ouvrages signés de son nom comme on les lisait avant qu'il n'invente Émile Ajar. Et cela parce que l'ensemble de l'image que nous avons de lui s'est modifié, entraînant une transformation de l'ensemble de ses textes et conduisant certains critiques à les réévaluer.

Et l'on voit bien ainsi, avec ce dédoublement exceptionnel, à quel point l'auteur imaginaire, tout autant sinon plus que l'auteur réel et l'auteur intérieur, est une composante majeure de la création des œuvres comme de leur réception, puisqu'elle intervient à tout moment dans leur rencontre avec le lecteur par les jeux de séduction et de miroir qu'elle tend à susciter afin de le rendre captif (Bayard, 2010: 60).

Ese «desdoblamiento excepcional» que buscaba eliminar los prejuicios, provoca que se lea diferente a Gary/Ajar, convirtiéndose así en el único autor en la historia que ha ganado el premio Goncourt dos veces. Casos como el de Gary desestabilizan las nociones de unidad y coherencia que comporta la idea (o función) de autor y de obra (Compagnon, s/f: 8), pero también desafía la muerte del autor y el giro en los estudios literarios. Si consideramos que tanto «el autor imaginario» (la representación que los lectores se hacen del autor de la obra), como «el autor interior» (la parte secreta del autor en la que se efectúa el proceso creativo), y «el autor real» (persona física que crea la obra) (Bayard, 2010: 155) intervienen en este juego de seducciones y de espejos, pareciera que Bayard se suma a la problemática actual del autor, la cual se activa de nuevo cuando «se cuestiona la vieja división entre el "Texto" (obligatoriamente en mayúsculas) y el "contexto"» radicalizada con la «oposición casi sagrada entre el "yo creador" y el "yo social”» (Maingueneau, 2009: 50); aunque, tenemos que reconocerlo, se suma de una manera muy peculiar.

Por momentos podemos empezar a dudar si el libro de Bayard trata realmente sobre el autor pues en ningún momento, salvo cuando menciona a Barthes y a Foucault en la nota a pié de página, retoma los estudios sobre el autor. Sin embargo, al no separar claramente entre lo interno y lo externo (entre diegético y extradiegético, para retomar a Genette) nos permite evocar otros debates actuales sobre la autoría que en el caso de Gary resultan muy fructíferos. Tal es el caso de las nociones de «ethos» $\mathrm{y}$ «postura». Maingueneau describe tres instancias imbricadas: la persona (ser civil), el escritor (la función-autor en el campo literario), el escriptor (el enunciador del texto): «Así las cosas, estudiar una postura es abordar simultáneamente (y cruzar esos elementos, con la prudencia que esto requiere) las conductas del escritor, el ethos del escriptor y los actos de la persona» (Meizoz, 2009: 87). La noción de postura supera la división de las aproximaciones internas y externas del texto ${ }^{8}$, y concibe al autor como una imagen colectiva: «La postura se forja así gracias a la interacción entre el autor, los mediadores y los públicos, anticipando o reaccionando a sus juicios». La postura «se referiría a la imagen que el escritor construye a lo largo de una serie de obras firmadas con su nombre» (Meizoz, 2009: 85-89). Ya que la postura es acumulativa, nos ayuda a considerar, en retrospectiva, toda la compleja dimensión de los casos de Gary y Vian (de quien hablaremos más adelante) como un panorama complejo, aunque quizás tendríamos que hablar de

\footnotetext{
${ }^{8}$ En resumen «-Como resultado de un análisis interno, la noción de ethos discursivo concierne al discurso del escriptor. Como resultado de un análisis interno, la noción de imagen de autor concierne al discurso del escriptor en relación con las informaciones de las que dispone el lector sobre el escritor. -Rechazando la distinción entre lo interno y lo externo la noción de postura concierne a las conductas del escritor en relación con el discurso del escriptor y con los actos de la persona» (Meizoz, 2009: 93).
} 
posturas transgresivas. Dicho de otra manera, la noción de postura nos permite hablar de Gary y de Ajar y del sobrino, y del primer premio y del segundo premio, y de las consecuencias literarias y también de las políticas de esta historia, entre muchas otras cosas. La postura «nace de una sociología de las conductas» y «denota la manera mediante la cual un autor se posiciona singularmente, dentro del campo literario al elaborar su obra» (Meizoz, 2009: 89).

En esta misma latitud nos parece pertinente evocar la noción de ethos ya que nos permite analizar y explicar las diferencias entre los textos de Gary y aquellos firmados por Ajar pero, de manera más interesante aún, nos permite señalar las singularidades de cada texto, más allá de la función de autor que pretende unirlas coherentemente. Esto es posible pues «el ethos se infiere a partir del interior de un discurso»y designa «esa imagen que el escriptor da de sí mismo en un texto singular y que se limita únicamente a éste» (Meizoz, 2009: 88). Los textos de Vian y Gary resultan paradigmáticos de la noción de ethos, la cual «se origina en el discurso» y explica el engaño, el doble premio y el escándalo, pues es precisamente la singularidad discursiva la que hace posible este desdoblamiento que tanto ha sacudido a la institución literaria. Las particularidades con las que trabaja el ethos también deberían de servir para intentar reconocer las diferencias (e incluso incoherencias) entre varios textos de un mismo autor, y subrayar las ganancias estéticas de estos desdoblamientos.

Curiosamente en las lecturas de Meizoz también encontramos un cierto interés por la transgresión de límites y fronteras entre la ficción y la realidad, pues señala que en algunos casos como en Rousseau o en Celine «la imagen discursiva que el autor construye en el discurso, al imponerse a través de la circulación de sus escritos, tiende a devenir [...] un patrón para la conducta pública del escritor» (Meizoz, 2009: 89). Mientras que la apuesta de Meizoz para los estudios literarios actuales articula retórica y sociología, la de Bayard conjuga teoría y ficción. ¿Sería posible hacerlos dialogar aunque quizás la prudencia no sea parte de las reglas de éste último? Pareciera que en lugar de la imagen de autor ${ }^{9}$ que propone Ruth Amossy, la cual, recordemos, incluye textos de ficción y textos factuales, Bayard prefiere al autor imaginario, que incluye no solo el ejercicio de pensar y analizar esa imagen, sino también el de construir e inventar nuevas relaciones, lo cual sin duda reformula y reevalúa tanto la noción de autor como la dimensión textual. Tendríamos que volver a Barthes, una vez más, para re-introducir la palabra jouer, en toda la dimensión de la lengua francesa que va más allá de lo lúdico, para señalar la forma en que Bayard literalmente «ejecuta» los textos, al jugar tanto con el ethos del escriptor como con el escritor.

El tercer ejemplo de la segunda parte del libro, que presenta la puesta en perspectiva temporal, se titula «Alicia en el país de las maravillas, por un escritor surrealista». Con esa ironía que le caracteriza, Bayard no solo señala anacrónicamente la influencia de los surrealistas en esta obra, sino que además insiste en que Carroll tomó mucho de la obra de Joyce, en otra filiación inadvertida y poco estudiada por los especialistas del autor (Bayard, 2010: 73). Lewis Carroll también está

\footnotetext{
9 «En síntesis, el ethos discursivo del escriptor constituye, a mi parecer, uno de los elementos de la imagen de autor, pues está tejida a partir de múltiples tipos de información, intra y extratextuales» (Meizoz, 2009: 90).
} 
endeudado con el psicoanálisis: pensemos en el mundo subterráneo al que el conejo conduce a Alicia y el inconsciente, el universo de los sueños, pero también del delirio.

Desplazar a Lewis Carroll del siglo XIX al siglo XX significa, nos dice Bayard, transportarlo a otra época, lo cual no es nuevo en la historia de la literatura si recordamos al poeta inglés del siglo XVIII que atribuyó sus propias obras a un poeta escoses del siglo tercero:

\footnotetext{
Cette mise en perspective de Lewis Carroll revient à tirer toutes les conséquences de la théorie du plagiat par anticipation que j'ai développée ailleurs. S'il s'avère que certains écrivains ont anticipé certains auteurs encore à venir au point de donner le sentiment de les avoir copiés, il n'est pas infondé alors, dans une histoire renouvelées de la littérature, de les placer après ceux qu'ils ont pillés, et donc de ne pas hésiter à les changer de période (Bayard, 2010: 75).
}

Lo malo de este gesto, confiesa el autor, es que pierden el carácter premonitorio: verlos como plagiadores en lugar de cómo precursores reduce su originalidad; pero lo bueno es que dinamiza, reactualiza, lo que ya es visto como un estereotipo de Alicia en el país de las maravillas. El contexto cambia y el texto se relaciona directamente con otras obras y adquiere una dimensión y una gravedad que no tenía. Recordando que el surrealismo nace de las ruinas de la primera guerra mundial cuestionando el orden político y social del momento, impugnando al mismo tiempo la concepción tanto del lenguaje como de la razón que predominaba en aquella época, Bayard propone entonces ver a Alicia en este nuevo contexto, cargada «de una violencia contra el poder» que no forma parte necesariamente de su creación: «Leur caractère ludique s'estompe au bénéfice d'une remise en question de toutes les formes de domination que l'être humain est en mesure d'exercer sur les autres créatures», dominación además ligada a un cierto ejercicio del lenguaje (Bayard, 2010: 76).

Cuando Compagnon hace un recuento de las nociones que se han relacionado en la historia de la literatura con la del autor, recuerda términos vecinos como: la biografía, el retrato y la intención; o los más modernos: la firma, la propiedad y el derecho de autor; pero también incluye algunas transgresiones como la parodia, el pastiche (las cuales, señalemos de paso, son constantes en la llamada literatura posmoderna) y por supuesto el plagio: «qui, a contrario, permettent de mieux saisir la notion positive d'auteur» (s/f: 1). En este contexto sin duda estaríamos tentados a ubicar el proyecto de Bayard como perteneciente al posmodernismo, pero precisamente a caballo entre teoría y ficción. Estamos pues frente a un proyecto teórico-crítico-ficticio con una complejidad lúdica e inventiva que aún no encuentra horizonte de recepción. ¿Cómo ignorar una suerte de desfamiliarización operando, esta vez, en la teoría?

\section{III}

Cada parte del libro de Bayard genera nuevas y diferentes reflexiones. Como hemos visto las modificaciones pueden ser diversas, y lo que se transgrede es la prohibición implícita de no modificar al autor (Bayard: 2010, 149). En el texto que nos presenta de Kafka se resaltan ciertas problemáticas en torno a la obra, las cuales eran más manifiestas en el otro autor; en otros casos nos ayudan a evidenciar la modernidad de un texto, como La Ética de Freud, o a modificar como en Ajar 
la mirada que arrojamos sobre la obra, al liberarla de atavismos anteriores. Finalmente «El grito» de Schumann hace dialogar a las artes de otra manera (Bayard, 2010: 149). Así nos damos cuenta de «le champ immense de recherches qui s'ouvre dès lors que l'on accepte cette idée qu'il est légitime de modifier les auteurs en partie ou en totalité» (Bayard, 2010: 150). Incluso a los escritores y artistas se les abren nuevos caminos.

Mientras que para Barthes imponer un Autor a un texto significa inmovilizarlo (Barthes, 1968: 68) y es un obstáculo para la libertad de la lectura (Compagnon, s/f: 3), en Bayard las nuevas asignaciones movilizan la riqueza textual que varía con cada contexto. Si efectivamente algunos críticos buscan la intención del autor, otros se alejan de ésta para interpretar el texto, y una tercera alternativa considera al lector como el criterio de la significación literaria, el texto de Bayard no pertenece estrictamente hablando a ninguno, pero al mismo tiempo parece tocar y problematizar las tres aproximaciones que han dominado los estudios literarios. La aparente paradoja es que, aunque parece que nos está hablando del autor, no está lejos de la idea de Blanchot de que toda lectura anula al autor para hacer del texto una obra impersonal (Blanchot, 1955: 256). Si hasta el momento habíamos pensado que está poniendo el acento en el autor, como el título parece indicarlo, en sus lecturas no hay dominio intencional, ni regresa al individualismo humanista propio del Autor. De hecho la intencionalidad pareciera desplazarse irónicamente al terreno del lector, por lo menos en algunos casos, es decir, podríamos incluso hablar de intención del lector, pues cada cambio de autor no hace más que reactivar el texto de una forma diferente abriendo así, aún más, el horizonte de las posibles interpretaciones.

Bayard conoce los riesgos de su proyecto y los afronta con ironía y un gran sentido del humor, confesando que este nuevo tipo de crítica sin duda será rechazada por los que defienden una historia de la literatura tradicional. Pero si estos dicen que las atribuciones son un simple error, implicaría pensar que la supresión del error nos llevaría de nuevo al autor real, cuando en realidad solo nos conduce a otra construcción, a otro autor imaginario (o imagen de autor, según el grado de prudencia del crítico), «construit à partir des convenances d'une époque et des fantasmes individuels de certains lecteurs» (Bayard, 2010: 151). Regresaremos más adelante a esta idea de «fantasmes individuels», pero señalemos por el momento cómo, pese al título del libro (¿Y si las obras cambiaran de autor?) y la importancia del autor que no hemos dejado de señalar, el lector también se encuentra en un primer plano. Es por eso que Motte señala que «Bayard has every reason to anticipate that we will accept the contract he tenders, for he wagers heavily upon our readerly desire, and more precisely still upon our wish to make a difference in the fictional worlds that we may encounter» (2011: 290). Coherente con su proyecto, en la obra de Bayard los contratos no solo pertenecen a la ficción, sino también a la teoría y a la crítica.

Una cosa es clara, los estudios literarios, pero en particular la literatura comparada se transforma y enriquece (Bayard, 2010: 150) y los horizontes de expectativas se desplazan en este libro (y proyecto en general) imposible de clasificar. Pero este «modelo intervencionista», en donde la intervención se convierte en un modo de interpretación, también evoca indirectamente a la teoría o 
estética de la recepción cuando nos dice que el lector y la crítica deben completar los mundos fragmentados de la literatura pues siempre son incompletos. ¿Como no pensar en un primer momento en Iser y las indeterminaciones que señala en los textos literarios? ¿Cómo no evocar a Jauss y la fusión de los horizontes históricos tanto del texto como del lector? Si reflexionamos una vez más en su lectura de Alicia, nos damos cuenta que cualquier lector actual lee el texto bajo la luz tanto del psicoanálisis como del surrealismo (precisamente en esa fusión de horizontes), a menos que sea posible una suerte de epojé, para poner entre paréntesis nuestros conocimientos sobre ambos. Dicho de otra forma, cuando leemos hoy a Alicia, consciente o inconscientemente, con frecuencia proyectamos en nuestras lecturas ciertos rasgos de la herencia tanto del psicoanálisis como del surrealismo, pues resulta difícil suspender todo el conocimiento que tengamos al respecto ${ }^{10}$. Es por esto que resulta difícil no pensar que Bayard está retomando ciertos guiños de la Estética de la Recepción ofreciéndole al lector la libertad, tan añorada por muchos críticos, que ni Iser ni Jauss pudieron darle, pues como bien sabemos tenían que cuidarse de su peor enemigo: la subjetividad. Ésta es acogida por Bayard de forma peculiar pues la interpretación, además de delirante, es un fenómeno personal intenso, pues para él no existe texto literario independiente de la subjetividad de quien lo lee. Sin embargo, en su discusión sobre la subjetividad interpretativa es irónico, complejo y se burla de sí mismo (Motte, 2011: 275), desplazando así cualquier apuesta por esta terrible acosadora de la crítica; ¿qué antídoto más eficiente frente a la subjetividad que reír con ella, dialogar con ella, y al mismo tiempo burlarse de ella?

El lector se convierte sin duda en un activista de la crítica literaria (Motte, 2011: 275), y las últimas líneas del cuento de Borges resumen con bastante acierto, quizás, uno de los objetivos del libro de Bayard: «Menard (acaso sin quererlo) ha enriquecido mediante una técnica nueva el arte detenido y rudimentario de la lectura: la técnica del anacronismo deliberado y de las atribuciones erróneas [...]. Esa técnica puebla de aventura los libros más calmosos. Atribuir a Louis Ferdinand Céline o a James Joyce la Imitación de Cristo ¿no es una suficiente renovación de esos tenues avisos espirituales?» (1939: 450). Varios críticos han señalado la manera en que el texto de Borges ofrece una reflexión sobre la lectura, sobre la recepción del texto y el papel que juega el tiempo (Compagnon, s/f: 10). En este contexto, si Bayard nos exhorta a reconsiderar cómo interpretamos la ficción, y cómo leemos crítica (Motte, 2011: 291), también tenemos que reconocer su nueva manera de hacer teoría.

\section{Autor espectral}

Buscando un autor más apropiado para el texto, como lo sugiere el mismo Bayard, podríamos decir que ¿Y si las obras cambiaran de autor? tuvo que ser escrita por algún autor postestructuralista, pues son innumerables los ejemplos que este juego de retribuciones nos ofrece.

\footnotetext{
${ }^{10}$ Quiero agradecer a todos los miembros del Seminario Permanente de Teoría de la Facultad de Filosofía y Letras de la UNAM, tanto a maestros como a alumnos (en especial Mónica Quijano y Adriana de Teresa), por sus comentarios y sugerencias en torno a este texto, el cual se ha visto enriquecido de muchas formas para demostrar una vez más, de la mano de Bajtín y Barthes, que todo texto está hecho de escrituras múltiples, de innumerables voces.
} 
Señalemos cuando menos la pluralización de la identidad señalada en el heterónimo: Vernon Sullivan de Boris Vian. Con la publicación de la novela Escupiré sobre vuestra tumba del 46, la novela generó un gran escándalo por los temas de racismo, sexo y violencia. Pero no era lo mismo que el texto hubiera sido escrito por un francés blanco (Boris Vian) que por un norteamericano negro (Vernon Sullivan).

Boris Vian también engaña al público inventando un autor que no existe, o más bien transformándose en autor americano, generando así otro ethos, y por ende modificando retrospectivamente toda postura. El texto nos habla entonces de una forma de verdad disimulada, por la cercanía de Vian a la cultura americana a través del Jazz, y el impacto que tiene éste en su literatura, incluso en el ritmo: «Un cierto Americano» es parte de su personalidad. Este autor es verdadero y falso a la vez, «car un grand écrivain a toujours une personnalité multiple. Et c'est cette pluralité de son être qui lui permet de réinventer la langue. Il n'est pas seulement ce à quoi le réduit son nom en le simplifiant, mais aussi beaucoup plus que cela» (Bayard, 2010: 69-70). De una u otra forma todos estamos compuestos de múltiples personas, pero los escritores las hacen surgir más que cualquier otro, siendo Pessoa un magnífico ejemplo.

Aceptar la paradoja de que un autor es verdadero y falso a la vez, así como la riqueza de la identidad múltiple solo es posible en pluma de un postestructuralista, o quizás de algún protopostestructuralista como Bajtín ${ }^{11}$, magistral también, aunque por razones políticas, en los juegos de máscaras autorales. Podríamos pensar que el autor es B: Barthes o Blanchot y sus escrituras neutras, pues finalmente el libro nos dice que todos son escritores de paso y los proyectos se parecen y se confunden en «ese texto único que nos precede» (Bayard, 2010: 114).

Sin embargo, para poder dimensionar la profundidad teórica-filosófica del texto, debemos aceptar que el autor de ¿Y si las obras cambiaran de autor? en realidad es Jacques Derrida. Y aunque podríamos demostrarlo capítulo tras capítulo, nos limitaremos a señalar algunos guiños y sus consecuencias. Desde el principio lo dice: «puisque la question de savoir qui est Homère demeurera à jamais dans le domaine de l'indécidable» (2010: 27), en realidad lo que hacemos es construir un autor imaginario: este último agrupa todas las imágenes y las fantasías (les fantasmes) que podemos desarrollar del autor (2010: 38-39). Como bien sabemos el neologismo «indecidible» fue forjado por Derrida $^{12}$ y refiere a la imposibilidad de determinar algo con exactitud, no porque estemos destinados al fracaso, sino porque distintas lecturas son igualmente posibles. La indecidibilidad es uno de los

\footnotetext{
11 «A pesar de que sea imposible la fusión entre el mundo representado y el creador, a pesar de la estabilidad de la frontera principal entre ellos, ambos están estrechamente ligados y se encuentran en permanente interacción [...] La obra y el mundo representado en ella se incorporan al mundo real y lo enriquecen; y el mundo real se incorpora a la obra y al mundo representado en ella, tanto durante el proceso de elaboración de la misma, como en el posterior proceso de su vida, en la reelaboración constante de la obra a través de la percepción creativa de los oyentes-lectores [...] incluso puede hablarse de un cronotopo creador en el que tiene lugar ese intercambio entre la obra y la vida, y en el que se desarrolla la vida específica de la obra» (Bajtín, 1973: 404). Con una lectura detenida podemos señalar un ir y venir de la frontera que Bajtín señala entre el mundo creado del texto, y el mundo creador del autor-lector, dicho en otras palabras entre ficción y realidad; aunque por momentos parezca muy estable, podemos ver la forma en que una cierta contaminación y una pequeña fisura está siempre presente.

${ }^{12}$ Lo mismo podríamos decir de la palabra diseminación que aparece al final del libro en el glosario.
} 
efectos más visibles de la deconstrucción, y a veces proviene de una producción de verdaderas polifonías poéticas filosóficas (Ramond, 2001: 44-45), como es el caso de ¿Y si las obras cambiaran de autor? en donde no hay filiación definitiva, tejiéndose sin cesar nuevas relaciones entre escritores y textos a través de lo que el filósofo llama «atribución móvil». Preservar el dinamismo del texto, finalmente, siempre ha sido parte importantísima del pensamiento deconstructivo.

Cuando Derrida insiste en que la parte ficticia nunca está ausente, y sin duda hay un «travail d'imagination que tout nom d'auteur suscite naturellement chez le lecteur» (2010: 28), una vez más está retomando la idea de que los límites y las fronteras que separan realidad y ficción, historia y realidad, pero también teoría y literatura, lenguaje y meta-lenguaje nunca son tan fijos y estables como se pretende. Manuel Asensi lo explica de la siguiente forma: «Derrida señala el carácter de escritura de la filosofía. Es decir la filosofía no es un metalenguaje externo a la teoría o a la literatura. La relación entre los tipos de lenguaje es compleja». Y aclara:

No estamos diciendo que todo sea literatura, sino que todo texto posee unas fisuras entre su querer ser (no podemos desde luego, olvidar la especificidad deseada por determinados discursos: la filosofía como discurso transparente, la literatura como ficción, el metalenguaje como exterioridad) y su otro (la filosofía como un género de escritura-ficción, la literatura como discurso epistemológico, el metalenguaje como interioridad) que lo tornan fragmentario y lo separan de toda pretendida autonomía y unidad de sentido (Asensi, 1990: 51).

La deconstrucción de la idea de autonomía y de unidad de sentido pareciera ser uno de los hilos conductores de ¿Y si las obras cambiaran de autor? Retomemos un ejemplo más de la tercera parte del libro, en donde se realizan los cambios completos de autor, y que se titula: Lo que el viento se llevó, de Léon Tolstoï: «Il n'existe pas à ma connaissance une seule étude critique qui tente d'expliquer les raisons qui ont conduit le grand romancier russe Léon Tolstoï à s'exiler de son pays par l'imagination et à écrire cette vaste fresque sur la guerre de Sécession qu'est Autant en emporte le vent» (2010: 93). Tolstoï, nos dice el autor de esta atribución móvil, sin lugar a dudas pensaba en Rusia mientras escribía este texto: «Il est vraisemblable qu'à travers Gérald O’Hara c'est Tolstoï luimême qui dit son amour pour la terre russe, comme pourrait le faire en des termes proches le Levine d'Anna Karénine» (2010: 95). La tierra de Rusia y de estados unidos se superponen una a la otra como un tipo de «palimpsesto involuntario», nos dice el autor. Y aquí, en una franca sintonía con la contaminación deconstructiva nos dice «Le cadre historique est fortement marqué par la volonté de transposition, au point que, là encore, il n'est pas toujours aisé de faire la distinction entre l'histoire américaine et l'histoire russe, qui finissent par se mêler indissolublement l'une à l'autre» (2010: 97).

Pero el momento más revelador del texto, como texto deconstructivo, se encuentra cuando señala: «Dès lors que l'on s'est fait à l'idée qu'il [Tolstoï] est bien l'auteur d'Autant en emporte le vent, la marque de l'écrivain se retrouve en de nombreuses pages du livre, et en premier lieu dans le portrait de son extraordinaire héroïne» (2010: 95). La marca del escritor, ¿es decir el estilo, aquello que, como habíamos señalado es intra-textual y extra-textual al mismo tiempo? ¿No son precisamente las marcas de Derrida las que estamos señalando en este momento en ¿Y si las obras cambiaran de autor?? La marca (marque o trait) es precisamente una noción recurrente en el 
pensamiento derridiano, de hecho aparece en la «Ley del género» para explicar por qué no hay género puro, y por qué siempre hay contaminación genérica (tanto literaria como sexual, entre muchas otras), pero sobre todo es la que hace posible el cambio de autor en el texto que nos ocupa hoy. Detengámonos un momento en una de las hipótesis de Derrida en «La ley del género»:

Tout texte participe d'un ou de plusieurs genres, il n'y a pas de texte sans genre, il y a toujours du genre et des genres mais cette participation n'est jamais une appartenance. Et cela non pas à cause d'un débordement de richesse ou de productivité libre, anarchique et inclassable, mais à cause du trait de participation lui-même, de l'effet de code et de la marque générique. En se marquant de genre, un texte s'en démarque. Si la remarque d'appartenance appartient sans appartenir, participe sans appartenir, la mention de genre ne fait pas simplement partie du corpus (Derrida, 1986: 264).

Es decir, lo que hace que un texto participe de un género literario son ciertas marcas que nosotros podemos identificar y que nos van a ayudar a clasificarlo, pero al mismo tiempo esas marcas, para que sean marcas, tienen que ser iterables, es decir repetibles en otro contexto (y por tanto en otros géneros), lo cual imposibilita que pertenezca simplemente a ese género. Un texto, parece estar diciendo esta vez Derrida en ¿Y si las obras cambiaran de autor?, no sabrá pertenecer a ningún autor. El estilo, que siempre se relaciona con la firma autoral, es como el nombre propio, se desapega de su portador porque es una marca iterable, que puede repetirse o copiarse siempre en otro contexto. El estilo como el nombre propio siempre es impropio (Bennington, 1991: 102) pues cualquiera puede usurparlo. Si consideramos que cada nueva asignación de autor en el texto implica un contexto diferente para cada texto, tenemos que recordar que el filósofo lo ha dicho hasta el cansancio: ningún contexto podrá saturar, agotar los significados de un texto (Derrida, 1990). ¿Ysi las obras cambiaran de autor? es la consecuencia lógica del pensamiento derridiano y de la continua re-contextualización propia de todo signo, de toda marca ${ }^{13}$.

De hecho cuando retoma a Borges en ¿Y si las obras cambiaran de autor? nos dice, reconociendo la gran influencia del escritor argentino en su pensamiento sobre la iterabilidad y la infinita re-contextualización: «C'est à cette expérience que se livre Borges dans sa célèbre nouvelle sur la réécriture du Don Quichotte en montrant que le même passage, écrit dans les mêmes termes à des siècles de distance par Cervantes et par Pierre Ménard, cesse d'être le même passage» (2010: 76). Compagnon también lo había señalado: son el mismo texto, pero al mismo tiempo dos textos diferentes (s/f: 10). Cambia el contexto y parece cambiar la intención (¿pero de quién?), un texto puede tener sentidos muy distintos dependiendo del contexto tanto de producción como de recepción.

¿Y si las obras cambiaran de autor? de Jacques Derrida no debe sorprendernos, pues retoma autores admirados y abordados antes por el filósofo como Joyce y Kafka, pero sobre todo Borges y Shakespeare. Lo que en otros textos llama «literatura auto-reflexiva» ${ }^{14}$, en este texto surge como

\footnotetext{
13 También podemos evocar cuando Asensi señala que el trabajo de la citacionalidad derridiana puede entenderse como una intertextualidad radicalizada, aunque la diferencia entre ambas sería que la intertextualidad busca una unidad coherente, convirtiéndose en un solo cuerpo, mientras que la citacionalidad derridiana no lo hace. Recordemos que la citacionalidad es otro nombre de la constante re-contextualización.

14 Aquí tendríamos entonces que reconocer (¿de nuevo?) la manera como Barthes acecha el libro ¿Y si las obras cambiaran de autor?, pues en El grado cero de la escritura nos dice que la literatura seria se cuestiona a sí misma, y cuestiona al mismo tiempo las convenciones a través de las cuales la cultura ordena el mundo.
} 


\section{Gabriela García Hubard}

«novela crítica», la cual muestra sus principios de construcción, es consciente de su herencia literaria, e invita al lector a ser aún más crítico. Por eso Motte señala que el autor del modelo intervencionista sabe que la metalepsis fragiliza las distinciones mostrando así las paradojas de la representación narrativa (2011: 292). En este contexto no podemos negar que el modelo intervencionista se suma al híper-análisis, al análisis interminable propio de la differance. Pero lo que resulta realmente sorprendente es que, por primera vez en su corpus, podemos decir que el filósofo escribió un texto muy fácil de leer, aunque no podamos hablar de transparencia, pues sigue siendo un texto difícil de clasificar. Este texto también podría servir de ejemplo para los detractores de la deconstrucción derridiana, quienes solo ven en su pensamiento un simple juego del lenguaje propio del ámbito literario.

Pero el hecho de que retome una vez más a Shakespeare, como ya lo había hecho en Espectros de Marx, nos permite entender que el sintagma clave para comprender y justificar las anacronías presentadas en ¿Y si las obras cambiaran de autor?, es el de Hamlet: «the time is out of joint». Esta temporalidad dislocada entre fantasmas y fantasías, que en el pensamiento derridiano en realidad gobierna toda la temporalidad humana, nos permite leer en eco estos dos libros del autor para explicar que la manera más adecuada hoy en día de referirse a ese mito y a ese tabú, al caleidoscopio autoral que no deja de ocuparnos y preocuparnos, es la noción de «autor espectral». Aunque el filósofo no hable específicamente del autor espectral, creemos que es la mejor manera de conjugar el autor imaginario de su último texto ¿Y si las obras cambiaran de autor? influenciado por Borges, $\mathrm{y}$ la lógica de la espectralidad de Espectros de Marx influenciada por Shakespeare. Quizás la palabra clave que subyace en el autor espectral es la de «fantasme», palabra francesa que, como ya vimos, significa tanto espectro como construcción imaginaria, alucinación y deseo, recuerdo que acecha. ¿No es todo esto lo que conforma hoy en día la noción del autor? Incomoda, asusta, fascina, seduce, nos invita a construirlo, y nos permite desplegar nuestras fantasías.

Siguiendo la lógica de la espectralidad no debemos revelar el secreto del fantasma, más bien tendría que interesarnos el misterio, pues si no hubiera nada secreto en los grandes autores no habría legado. Estos autores espectrales no se pueden agotar ni entender por completo, no es posible su apropiación, por eso continúan acechando los textos en todos los tiempos. El secreto, no es un conocimiento escondido que puede ser revelado por completo, el secreto señala los límites del saber, pero es gracias a esta imposibilidad de saber absoluto que se puede continuar dialogando con los espectros. Tiene que haber suficiente secreto en los autores espectrales para desafiar a la interpretación, por lo que el pensamiento derridiano hace ese llamado al «riesgo sin límites de la interpretación activa» (Derrida, 1996: 26), llevada a cabo a través de la crítica intervencionista.

Con la figura del «autor espectral» no se trata de regresar a la figura de Autor, ni de restaurar su poder y autoritarismo. No es una figura idéntica a ella misma, ni eterna; la figura del autor espectral desestabiliza las nociones de homogeneidad y unificación. El autor espectral excede y deconstruye las oposiciones binarias, sobre todo la de realidad y ficción, pero también la de autor y texto, así como la de crítica y ficción. El autor espectral es indispensable pero insuficiente, está «out 
of joint»y por ende nos salva del totalitarismo, de la inmovilidad. Abre el texto al avenir. El autor espectral deconstruye la «presencia como realidad efectiva y como objetividad», está y no está, está vivo y muerto al mismo tiempo. El autor espectral siempre regresa, en cada lectura, pero no sabemos controlar sus idas y sus venidas.

La lógica de la espectralidad del pensamiento derridiano perturba e irrumpe el orden autoral. Los que no creen en fantasmas, nos dice el filósofo, normalmente creen en la frontera tajante entre la realidad y la ficción, lo vivo y lo no vivo (Derrida, 1993: 33). La «crítica intervencionista» puesta en práctica con el cambio de autor es, me parece, una manera de mostrar el poder de irrupción del autor espectral. Pero habrá que preguntarse una y otra vez, ¿debemos ser prudentes con nuestros fantasmes en este contexto?

\section{Referencias bibliográficas}

Amossy, R. (2009): «La doble naturaleza de la imagen de autor», en J. Zapata, comp. y trad., La invención del autor. Nuevas aproximaciones al estudio sociológico y discursivo de la figura autorial. Colombia, Universidad de Antioquia, 2014, pp. 66-84

AsEnsi, M. (1990): «Crítica límite / El límite de la crítica» en Teoría literaria y deconstrucción. Madrid, Arco libros.

BAJTIN, M. (1973): «“Observaciones finales” de Las formas del tiempo y el cronotopo», en Teoría y estética de la novela: trabajos de investigación. Madrid, Taurus, 1989, pp. 393-409.

BARTHES, R. (1968): «La mort de l'auteur» en Le bruissement de la langue. París, Seuil, 1984, pp. 63-69.

(1973): Le plaisir du texte, París, Seuil.

BAYARD, P. (2000): Comment améliorer les ouvres ratées?. París, Minuit.

- (2005): Demain est écrit. París, Minuit.

- (2007): Comment parler des livres que l'on n'a pas lus?. París, Minuit.

- (2008): L'Affaire du chien des Baskerville. París, Minuit.

- (2009): Le Plagiat par anticipation. París, Minuit.

- (2010): Et si les ouvres changeaient d'auteur?. París, Minuit.

Bennington, G. (1991): «Derridabase», en Jacques Derrida. París, Seuil.

BLANCHOT, M. (1955): L'Espace littéraire. París, Gallimard.

Borges, J. L. (1939): «Pierre Menard, autor del Quijote» en Obras completas. Buenos Aires, Emecé, 1987, pp. 444-450.

COMPAGNON, Antoine (s/f): «Théorie de la littérature: Qu'est qu'un auteur?» en http://www.fabula.org/compagnon/auteur.php

DERRIDA, Jacques (1986): «La loi du genre», en Parages. París, Galilée, pp. 249-287.

- (1990): Limited Inc. París, Galilée. (1993): Spectres de Marx. París, Galilée. 
156 Tropelías. Revista de Teoría de la Literatura y Literatura Comparada, 24 (2015)

Gabriela García Hubard

B. StIEGler, eds. (1996): Echographies of Television. Trad. de Jennifer Bajorek. Cambridge, Polity, 2002.

DiAZ, J.-L. (1993): «L'écrivain comme Fantasme», en C. Coquio y R. Salado, eds., Barthes après Barthes, une actualité en questions. Actes du colloque international de Pau. Pau, PUP, pp. 77-87.

Foucault, M. (1969): «Qu'est-ce qu'un auteur ?» en Dits et écrits I, París, Gallimard, 2001, pp. 817-849.

GenetTe, G. (1972): Figures III. París, Seuil, 1972.

MaingueneAu, D. (2009): «Autor e imagen de autor en análisis del discurso», en J. Zapata, comp. y trad., La invención del autor. Nuevas aproximaciones al estudio sociológico y discursivo de la figura autorial. Colombia, Universidad de Antioquia, 2014, pp. 48-66.

MeIzoz, J. (2009): «Aquello que le hacemos decir al silencio: postura, ethos, imagen de autor», en J. Zapata, comp. y trad., La invención del autor. Nuevas aproximaciones al estudio sociológico $y$ discursivo de la figura autorial. Colombia, Universidad de Antioquia, 2014, pp. 84-96.

Mотте, W. (2011): «Pierre Bayard's Wormholes», Studies en 20th \& 21st Century Literature, 35/2, artículo 7, http://dx.doi.org/10.4148/2334-4415.1751.

RAMOND, C. (2001): Le vocabulaire de Derrida. París, Ellipses. 